\title{
Research Data Management in Context: Embedding Research Data in Open Scholarship at Indiana University
}

\author{
Jamie Wittenberg \\ Research Data Management and Head, Scholarly Communication Department \\ Indiana University, Bloomington \\ jvwitten@indiana.edu
}

\section{Background}

A research data management program was established in 2011 with the hire of the first Research Data Management Librarian at the Indiana University (IU) Libraries, a position initially appointed to the Library Technologies unit. Over time, this position moved to the Scholarly Communication department. Research data services also emerged in the IU leveraged service provider, University Information Technology Services (UITS)-Research Technologies. Since 2011, researchers have been increasingly expected to plan for, curate, and publicly share their research output including journal articles, code, visualizations, underlying datasets, and documentation. The IU Bloomington campus support for researchers navigating these new requirements has been dispersed even with highly leveraged IT services. Some data services have emerged in the Libraries, University Information Technology Services, and the Office of the Vice Provost for Research. In practice, individuals within these units collaborate to offer support to faculty and graduate students working to comply with funder policies at all stages of the research process. Collaboration is informal but frequent.

The IU Libraries are working to implement a Research Data Service that formalizes these relationships. Implementing a Research Data Service that is sustainable and flexible requires incorporation into broader university services. In the IU Libraries, research data services are embedded in the Scholarly Communication department. These services include support for data management planning, data curation, publishing, sharing, storage, and transfer. Typically, services are provided as part of departmental training and outreach efforts, individual researcher consultation, or support using departmental data management tools. 
Research data services align closely with existing scholarly communication services because both areas work directly with faculty and students on optimizing research output and communication. Typically, consultations are sought later in the research process, during the publishing phase. Federal agency compliance inquiries often span research data management and scholarly communication because open access and open data sharing policies are similar in nature. At Indiana University, we are actively working to contextualize research data services as part of scholarly communication services and open scholarship more broadly.

\section{Current Infrastructure}

\section{IUScholarWorks}

Long-term data preservation and publishing is supported by the institutional repository, IUScholarWorks. The repository stores datasets over 150MB on the university's tape-based archive system (geographically distributed HPSS). This archive system, the Scholarly Data Archive, does not impose limits on file size for most users. Once data are available in the Scholarly Data Archive, the Libraries create a permanent URL to the archived bitstream and embed it in the item record/registry in IUScholarWorks. This PURL initiates a download, meaning that a user never needs to interact directly with the Scholarly Data Archive or leave the institutional repository in order to access a dataset.

\section{NSF Jetstream}

The IUScholarWorks repository also supports archiving virtual machines through its integration with Jetstream ${ }^{1}$, a self-provisioned, scalable science and engineering cloud environment (\#ACl1445604) funded by the National Science Foundation. Jetstream enables users to create personal, customized virtual environments that can be published in the IUScholarWorks ${ }^{2}$ institutional repository. On the back end, the virtual machines are archived in the Scholarly

\footnotetext{
${ }^{1}$ Stewart, C.A., Cockerill, T.M., Foster, I., Hancock, D., Merchant, N., Skidmore, E., Stanzione, D., Taylor, J., Tuecke, S., Turner, G., Vaughn, M., and Gaffney, N.I., Jetstream: a self-provisioned, scalable science and engineering cloud environment. 2015, In Proceedings of the 2015 XSEDE Conference: Scientific Advancements Enabled by Enhanced Cyberinfrastructure. St. Louis, Missouri. ACM: 2792774. p. 1-8. http://dx.doi.org/10.1145/2792745.2792774 and John Towns, Timothy Cockerill, Maytal Dahan, Ian Foster, Kelly Gaither, Andrew Grimshaw, Victor Hazlewood, Scott Lathrop, Dave Lifka, Gregory D. Peterson, Ralph Roskies, J. Ray Scott, Nancy Wilkins-Diehr, "XSEDE: Accelerating Scientific Discovery", Computing in Science \& Engineering, vol.16, no. 5, pp. 62-74, Sept.-Oct. 2014, doi:10.1109/MCSE.2014.80

2 Jetstream collection in IUScholarWorks Repository - https://scholarworks.iu.edu/dspace/handle/2022/19557
} 
Data Archive. Upon request, Jetstream VMs can have DOIs minted to facilitate sharing and citation.

\section{Open Journal Systems}

The Libraries are exploring options for integrating research data publishing support into the existing publishing infrastructure. The Libraries, in collaboration with the University Press, currently operate a rapidly growing open access publishing program. The program uses the open-source Open Journal Systems platform. Most of the journals participating in the program have one or more Indiana University faculty editors. In the last year, there have been two requests for data publication within Open Journal Systems. The Libraries are currently in the process of migrating to the newest version of Open Journal Systems (OJS3) in order to gain access to improved functionality for data publishing.

\section{Imago}

Imago, a collaboration between the Indiana University Libraries and the Center for Biological Research Collections, is digital repository for scientific specimens built in Fedora 4 with a Sufia 7 Samvera head. Imago supports sharing and preservation for biodiversity digital specimen data with emphasis on data from the IU Paleontology Collection, IU Herbarium, and William R. Adams Zooarchaeology Collection. The repository is designed to support three-dimensional data. The Imago team has implemented the IIIF-based Universal Viewer ${ }^{3}$ to render threedimensional digital objects

\section{Research Data Case Studies - Indiana University Bloomington}

\section{Humanities}

A professor in a humanities discipline was referred to the scholarly communication department by another librarian. The patron requested support writing a data management plan (DMP) for a National Endowment for the Humanities grant proposal. During the data management plan consultation, the librarian created a DMPTool data management plan and advised on completing the plan. The patron completed their DMP based on these recommendations and requested review from the librarian. Using the built-in DMPTool review toolkit, the librarian reviewed the final DMP and wrote a letter of support for the grant proposal. The submitted DMP stated that an expected $11 \mathrm{MB}$ of tabular data would be published in the IUScholarWorks repository. DOls would be minted for the repository record and embedded in publications.

\footnotetext{
${ }^{3}$ http://player.digirati.co.uk/
} 
Following a consultation with the librarian about data sharing, the patron also elected to make all publications openly available in the institutional repository.

\section{Physical Sciences}

A professor in a physical science field emailed their liaison librarian regarding compliance with the Department of Energy public access policy. The patron sought assistance in complying with both the federal agency policy and their society journal's publishing agreement. The patron also wished to generate file-level DataCite DOls that correlate to figures in the published article. Because each of the 50 files were $10 \mathrm{MB}$ at maximum, the data remained on DSpace servers accessible through IUScholarWorks. The society journal provided an exception in their publishing agreement for openly sharing the manuscript in response to federal agency requirements.

\section{Social Sciences}

A professor in a social science discipline is conducting human-subjects research. Some of these data include anonymized video where playback is desirable. The patron contacted the Scholarly Communication department directly by email. He had four requests:

1. Archive several terabytes of anonymized high-definition biomedical data

2. Create a landing page to provide context for and access to these data

3. Create recommended citations for these data to ensure appropriate attribution

4. Contribute new, related datasets to the archive over time

The circumstances of this study were well-suited to the integration between the IUScholarWorks repository and Avalon Media System, a platform created with Northwestern University to enable management of multiple media collections across a library system. The IUScholarWorks repository supports playback by making an access video available for streaming in Media Collections Online, an Avalon-based repository, and ensures preservation by depositing an archival copy of the video in the Scholarly Data Archive.

\section{Policy efforts}

The Libraries are working to unify research data support that is currently being provided in the Office of the Vice Provost for Research, University IT Service, and Libraries. A proposal for a joint program was reviewed in spring 2017 by the $\mathrm{ClO}$. Current efforts to establish a joint, university-level program include a working group appointed to investigate the feasibility of a shared Hyrax/Fedora repository, a grassroots-level attempt to collect research data use cases 
across campuses, and early collaboration with the university data stewards group responsible for administrative data management.

\section{Outreach efforts}

Because the IU Bloomington faculty adopted a campus wide open access policy in February 2017, the Scholarly Communication Department is working to leverage open access outreach efforts as opportunities to promote open data, reproducible research, and data sharing. As part of this effort, the department has framed research data management as one component within a suite of research services that support open scholarship more broadly. These services include open access, data management, copyright consultation, publishing, and open educational resources. A new website ${ }^{4}$ was created to provide access to these services.

\section{The Future of RDM Implementation}

Indiana University has made a commitment to migrate to a shared Fedora repository for all campuses. Our hope is that this shared infrastructure will foster more collaboration and reduce the technical silos created by dissimilar platforms. Library Technology is actively developing features that meet the IU community's needs. One exciting recent development is the emerging demand for resources related to publishing three-dimensional data. A group with representation from multiple campuses is working with research communities to establish minimum metadata standards for publishing these objects. Prototypes have been created in both Imago and Open Journal Systems.

Library research data services at IU are actively working to collect and publish data using workflows that are congruent with journal and monographic content. Like other kinds of research output, data should be collected and shared in areas that are relevant to the research and teaching community at an institution. Just as liaison librarians research and solicit feedback on collections to ensure the relevance of the resources in their subject area, libraries should be working to recruit content that includes data. Integrating research data services into the fabric of scholarly communication is expedient for libraries, sensible for researchers, and effective in working towards the goals of supporting effective research practices and building collections with research value.

\footnotetext{
${ }^{4}$ IU Libraries Open Scholarship Website - https://openscholarship.indiana.edu
} 